\title{
PEMETAAN INDEKS TINGKAT PELAYANAN JALAN PONOKAWAN SAMPAI JALAN MAYJEN BAMBANG YUWONO KRIAN SIDOARJO DENGAN METODE LINIER
}

\author{
Sarra Amanda Sinaga ${ }^{[1]}$, Siti Zainab ${ }^{[2]}$, Hendrata Wibisana ${ }^{[3]}$ \\ ${ }^{[1]}$ Alumni Teknik Sipil Universitas Pembangunan Nasional "Veteran" Jawa Timur \\ ${ }^{[2]}$ Departemen Teknik Sipil Universitas Pembangunan Nasional "Veteran" Jawa Timur \\ ${ }^{[2]}$ Departemen Teknik Sipil Universitas Pembangunan Nasional "Veteran" Jawa Timur \\ Email: hendrata2008@gmail.com
}

\begin{abstract}
ABSTRAK
Perkembangan kabupaten Sidoarjo bagian barat khususnya Kecamatan Krian memberikan pengaruh besar pada pertumbuhan kawasan di pinggiran kota. Dengan semakin bertambahnya jumlah dan aktivitas penduduk, pertumbuhan transportasi darat adalah salah satu bagian pokok yang tidak dapat dipisahkan dari aktivitas tersebut. Hal ini menyebabkan terjadinya permasalahan lalu lintas yang cukup kompleks terutama masalah kepadatan lalu lintas. Penelitian ini bertujuan untuk menganalisa Indeks Tingkat Pelayanan (ITP) dengan metode regresi linier pada ruas Jalan Ponokawan sampai dengan ruas Jalan Mayjen Bambang Yuwono di kota Krian. Survei dilakukan pada pagi hari (07.0009.00), siang hari (12.00-14.00) dan juga sore hari (16.00-18.00), dimana untuk menganalisa perhitungan volume lalu lintas, kapasitas ruas jalan, dan kecepatan arus bebas digunakan pedoman Manual Kapasitas Jalan Indonesia (MKJI) 1997. Sistem Informasi Geografis (SIG) dapat membantu untuk menyajikan informasi hasil analisa indeks tingkat pelayanan jalan berupa peta tematik yang mudah di pahami. Dari hasil analisa data maka dapat dilakukan perhitungan indeks tingkat pelayanan (a) pada masing-masing segmen dengan menggunakan metode regresi linear dan dari penelitian ini diperoleh hasil pada segmen I sebesar 0,093, segmen II sebesar 0,141, segmen III sebesar 0,074, segmen IV sebesar 0,210, segmen V sebesar 0,130, segmen VI sebesar 0,109, dan segmen VII sebesar 0,113 .
\end{abstract}

Kata kunci: Indeks Tingkat Pelayanan, Regresi Linier, Sistem Informasi Geografis (SIG)

\section{ABSTRACT}

The development of West Sidoarjo especially at Krian city has a major influence on the growth of suburban areas. By increasing the number and activity of the population, transportation is one of the principal parts that cannot be separated from the activity. This leads to quite complex traffic problems, especially traffic density problems. This research was conducted to analyze the Service Level Index (ITP) with linear regression method on Jalan Ponokawan until Jalan Mayjend Bambang Yuwono Krian. The survey was conducted in the morning (07.00-09.00), afternoon (12.00-14.00), and evening (16.00-18.00) to analyze the calculation of traffic volume, road capacity, and the speed of the free flow by using Manual Kapasitas Jalan Indonesia (MKJI) 1997. The Geographic Information System (GIS) can help to provide information on road service level index analysis in the form of thematic maps that are easy to understand. From the results of data analysis, a service level index (a) is calculated on each segment using linear regression method and the result of segment I is 0,093, segment II is 0.141, segment III is 0.074, segment IV is 0.210, segment V is 0.130, segment VI is 0.109, and segment VII is 0.113 .

Keywords: Service Level Index, Linear Regression, Geographic Information Systems (GIS) 


\section{PENDAHULUAN}

\subsection{Latar Belakang}

Perkembangan kabupaten Sidoarjo bagian barat khususnya Kecamatan Krian memberikan pengaruh sangat besar pada pertumbuhan kawasan pinggir kota tersebut. Kawasan di Sidoarjo barat yang perkembangannya cukup pesat merupakan dampak dari perkembangan kota Surabaya dan Sidoarjo secara global, terjadinya urbanisasi dan peluang kerja karena banyak perusahaan besar yang berdiri di wilayah Krian dan berdampak pada pertumbuhan jumlah penduduk dan peningkatan kualitas lingkungan. Seiring dengan bertambahnya jumlah penduduk dan aktivitas penduduk yang ditandai dengan semakin besar kebutuhan akan sarana dan prasarana, transportasi adalah salah satu bagian pokok yang tidak dapat dipisahkan dari kebutuhan-kebutuhan tersebut terutama transportasi darat. Hal tersebut menyebabkan terjadinya permasalahan lalu lintas yang cukup kompleks terutama terjadi penumpukan kepadatan lalu lintas (Afonso et al., 2019; Alekseeva et al., 2018; Li et al., 2017; Hendra Wibisana, 2007).

Permasalahan lalu lintas yang sering terjadi terutama pada ruas jalan arteri yang ramai adalah kemacetan lalu lintas (Jain et al., 2012; Lindsey \& Verhoef, 2000; Rhee et al., 2016), disamping efek buruk lainnya berupa kebisingan (Dewan \& Ahmad, 2007; Waqas et al., 2018; Hendrata Wibisana \& Utono, 2016), disamping itu bias disebabkan karena volume kendaraan yang melintas semakin meningkat pada saat jam-jam sibuk pagi hari dan sore hari serta berbagai aktivitas transportasi umum seperti angkutan umum dan kendaraan berat seperti truk dan container yang melintasi jalan tersebut.Selain itu kepadatan lalu lintas juga disebabkan oleh masyarakat sekitar yang tidak disiplin dalam berlalu lintas dan kegiatan lain yang mempengaruhi kelancaran arus lalu lintas seperti PKL, aktifitas penduduk sehari hari (bekerja, ke sekolah, berbelanja) yang selalu menggunakan sarana dan prasarana lalu lintas.

Penelitian ini bertujuan untuk menganalisa nilai Indeks Tingkat Pelayanan (ITP) pada ruas jalan Ponokawan sampai ruas jalan Mayjen Bambang Yuwono dengan menghitung volume kendaraan, kecepatan rata-rata, kapasitas jalan dan waktu tempuh. Dalam penelitian ini digunakan pendekatan regresi linier untuk memperhitungkan nilai Indeks Tingkat Pelayanan jalan (ITP). Hasil akhir yang diharapkan dari penelitian ini berupa informasi yang mampu memberikan gambaran berupa peta tematik dari nilai Indeks Tingkat Pelayanan jalan (ITP) dengan menggunakan teknologi aplikasi Sistem Informasi Geografis (SIG).

\subsection{Rumusan Masalah}

Berdasarkan latar belakang yang ada di dapatkan rumusan masalah sebagai berikut:

1. Berapa volume kendaraan pada kondisi saat ini?

2. Berapa rata-rata kecepatan arus bebas di ruas jalan tersebut?

3. Bagaimana nilai Indeks Tingkat Pelayanan dari masing-masing ruas jalan arteri? 
4. Bagaimana memetakan Indeks Tingkat Pelayanan (ITP) pada ruas jalan Ponokawan sampai jalan Mayjen Bambang Yuwono menggunakan Sistem Informasi Geografis (SIG)?

\subsection{Tujuan Penelitian}

Dari rumusan masalah didapatkan tujuan sebagai berikut:

1. Untuk menghitung volume kendaraan.

2. Menghitung rata-rata kecepatan arus bebas.

3. Menghitung nilai Indeks Tingkat Pelayanan (ITP).

4. Membuat peta tematisk Indeks Tingkat Pelayanan (ITP) pada ruas jalan Ponokawan sampai jalan Mayjen Bambang Yuwono.

\subsection{Batasan Masalah}

Penelitian ini mempunyai batasan masalah diantaranya:

1. Pengamatan hanya dilakukan pada ruas Jalan Ponokawan sampai ruas Jalan Mayjen Bambang Yuwono.

2. Pengamatan dilakukan pada pukul 06.00-08.00 dan pukul 12.00-14.00 serta pukul 16.0018.00 .

3. Perhitungan menggunakan Manual Kapasitas Jalan Indonesia (MKJI 1997).

4. Pengamatan hanya mengamati volume, kecepatan kendaraan, hambatan samping pada ruas jalan Ponokawan sampai ruas jalan Mayjen Bambang Yuwono.

5. Aplikasi yang digunakan pada tugas akhir ini adalah ArcGis Versi 10.3

\subsection{Lokasi Studi}

Lokasi penelitian dilakukan pada ruas Jalan Ponokawan sampai ruas jalan Mayjen Bambang Yuwono Krian Kabupaten Sidoarjo. Peta lokasi penelitian ditunjukkan pada gambar 1.1. berikut:

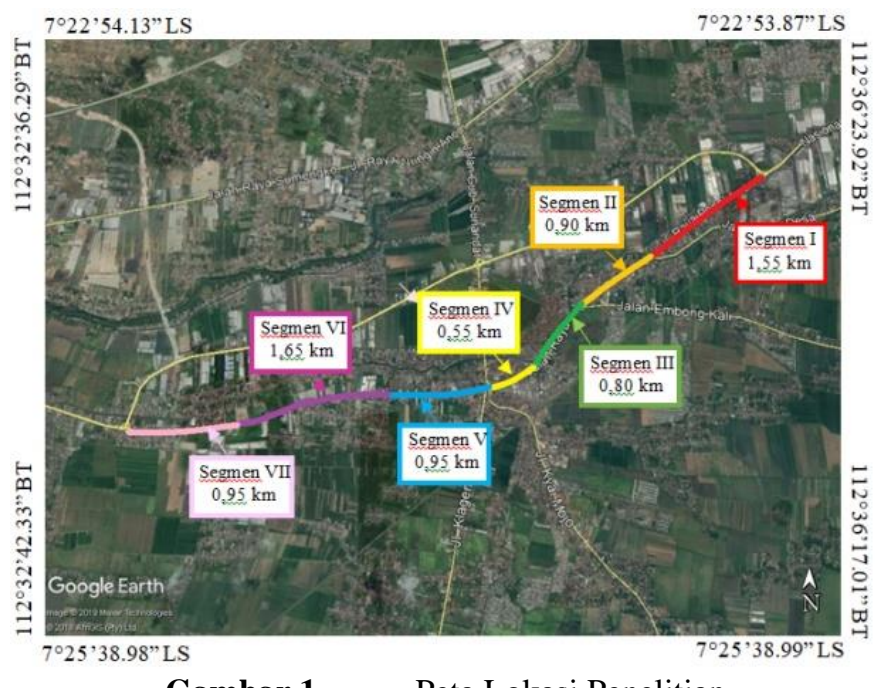

Gambar 1. Peta Lokasi Penelitian 


\section{TINJAUAN PUSTAKA}

\subsection{Karakteristik Arus Lalu Lintas}

Arus lalu lintas merupakan banyaknya kendaraan bermotor yang melewati titik tertentu per satuan waktu, dan dinyatakan dalam satuan kendaraan per jam ataupun smp/jam (Direktorat Jenderal Bina Marga 1997). Beberapa arus lalu lintas terbagi empat (4) jenis yaitu:

1. Kendaraan Ringan / Light vehicle (LV)

Kendaraan berdoa empat dengan jarak as 2,0 - 3,0 seperti mobil penumpang, pick up, truk 1 as yang sesuai dengan sistem klasifikasi Bina Marga.

2. Kendaraan Berat / Heavy Vehivle (HV)

Kendaraan bermotor yang memiliki 2 as atau lebih seperti bis, truk 2 as, dan truk 3 as atau trailer yang sesuai dengan sistem klasifikasi Bina Marga)

3. Sepeda Motor / Motor Cycle (MC)

Kendaraan bermotor dengan dua atau tiga roda seperti sepeda motor dan sepeda motor dengan side-passengers vehicle (kendaraan penumpang samping)

4. Kendaraan tak bermotor / Unmotorized Vehicle (UV)

Meliputi kendaraan beroda yang menggunakan tenaga manusia atau hewan seperti becak, sepeda, kereta kuda dan kereta dorong.

\subsection{Kapasitas}

Kapasitas didefinisikan sebagai arus maksimum melalui suatu titik jalan yang dapat dipertahankan per satuan jam yang melewati suatu titik jalan dalam kondisi yang ada.

Persamaan dasar untuk penentuan kapasitas adalah sebagai berikut:

Dengan:

$C=C_{0} \times F C_{W} \times F C_{S P} x F C_{S F} x F C_{C S}$

C $\quad=$ kapasitas $(\mathrm{smp} / \mathrm{jam})$

$\mathrm{C}_{0} \quad=$ kapasitas dasar $(\mathrm{smp} / \mathrm{jam})$

$\mathrm{FC}_{\mathrm{W}} \quad=$ faktor penyesuaian lebar jalan

$\mathrm{FC}_{\mathrm{SP}} \quad=$ faktor penyesuaian pemisah arah (untuk jalan tak terbagi)

$\mathrm{FC}_{\mathrm{SF}} \quad=$ faktor penyesuaian hambatan smaping dan bahu jalan

$\mathrm{FC}_{\mathrm{CS}}=$ faktor penyesuaian ukuran kota

\subsection{Kecepatan Arus Bebas}

Menurut MKJI (1997), kecepatan arus bebas dapat didasari dengan persamaan berikut:

Dengan:

$F V=\left(F V_{0}+F V_{W}\right) x F F V_{S F} x F F V_{C S}$

FV = kecepatan arus bebas kendaraan ringan $(\mathrm{km} / \mathrm{jam})$ 
$\mathrm{FV}_{0} \quad=$ kecepatan arus bebas dasar kendaraan ringan $(\mathrm{km} / \mathrm{jam})$

$\mathrm{FF}_{\mathrm{W}}=$ penyesuaian lebar jalur lintas efektif (penjumlahan) $(\mathrm{km} / \mathrm{jam})$

$\mathrm{FFV}_{\mathrm{SF}}=$ faktor penyesuaian hambatan samping dan lebar bahu atau jarak kereb penghalang

$\mathrm{FFV}_{\mathrm{CS}}=$ faktor penyesuaian untuk ukuran kota

\subsection{Hubungan Arus Lalu Lintas Dengan Waktu Tempuh}

Besarnya waku tempuh pada suatu ruas jalan sangat tergantung dari besarnya arus dan kapasitas ruas jalan tersebut. Hubungan antara arus dengan waktu tempuh dapat dinyatakan sebagai fungsi dimana jika arus bertambah maka waktu tempuh akan juga bertambah. Menurut Davidson (1966) dalam buku Perencanaan Permodelan Transportasi (Tamin, 2003) hal ini merupakan konsep dasar dari teori antrian yang menyatakan bahwa tundaan yang terjadi pada tingkat pelayanan dapat dinyatakan dengan persamaan berikut:

Dengan:

$$
W_{Q}=\frac{P^{2}}{[\lambda(1-\rho]}
$$

$\mathrm{W}_{\mathrm{Q}} \quad=$ tundaan per kendaraan

$\lambda \quad=$ tingkat kedatangan

$\rho \quad=\frac{\lambda}{\mu}$

$\mu \quad=$ tingkat pelayanan

Berdasarkan teori antrian stokastik untuk satu tempat pelayanan dengan sebaran pelayanan acak, besarnya waktu tunggu yang dialami oleh setiap kendaraan dengan sebaran kedatangan acak dapat dinyatakan dengan persamaan berikut:

$$
E_{w}=\frac{\rho}{[\mu(1-\rho)]}
$$

Karena $\mu=\frac{\lambda}{\rho}$ maka sebenarnya persamaan (4) sama dengan persamaan (3)

Konsep antrian dalam waktu pelayanan merujuk pada waktu minimum yang dibutuhkan kendaraan untuk melalui suatu ruas jalan sesuai dengan tingkat pelayanan jalan yang ada. Waktu pelayanan adalah waktu temput yang dibutuhkan ketika tidak ada kendaraan lain pada jalan tersebut (kondisi arus bebas). Sehingga, tundaan antrian dapat dipertimbangkan sebagai pertambahan waktu tempuh akibat adanya kendaraan lain yang dapat dinyatakan sebagai berikut:

Waktu tempuh $=$ waktu pelayanan + tundaan

Nilai nisbah tundaan antrian waktu pelayanan dapat diturunkan dengan urutan persamaan berikut:

$$
\begin{aligned}
& \frac{W_{Q}}{1 / \mu}=\frac{\rho^{2 \mu}}{[\lambda(1-\rho)]} \\
& \frac{W_{Q}}{1 / \mu}=\frac{\rho}{[(1-\rho)]}
\end{aligned}
$$


Jika waktu pelayanan adalah waktu tempuh pada kondisi arus bebas $\left(\mathrm{T}_{0}\right)$ maka persamaan (7) dapat dinyatakan dengan bentuk lain seperti persamaan berikut:

$$
\begin{aligned}
\frac{W_{Q}}{T_{0}} & =\frac{\rho}{[(1-\rho)]} \\
W_{Q} & =T_{0} \cdot \frac{\rho}{[(1-\rho)]}
\end{aligned}
$$

Tundaan yang terjadi disebabkan oleh suatu rangkaian antrian sehingga variasi pada waktu tempuh tergantung pada tundaan antrian. Oleh karena itu, persamaan harus dimodifikasi dengan memasukkan suatu faktor "a" (indeks tinkat pelayanan) yang besarnya tergantung dari karateristik ruas jalan dan tundaan akibat adanya kendaraan lain pada ruas jalan tersbut sehingga dihasilkan persamaan berikut:

$$
W_{Q}=T_{0} \cdot a \cdot \frac{\rho}{[(1-\rho)]}
$$

Selanjutnya, dengan memasukkan persamaan (10) ke persamaan (4), maka dihasilkan urutan persamaan berikut:

$$
\begin{aligned}
& T_{Q}=T_{0}+W_{Q} \\
& T_{Q}=T_{0}+T_{0} \cdot a \cdot \frac{\rho}{[(1-\rho)]} \\
& T_{Q}=T_{0}\left[1+a \frac{\rho}{(1-\rho)}\right] \\
& T_{Q}=T_{0}\left[\frac{1-(1-a) \rho}{1-\rho}\right]
\end{aligned}
$$

Dengan mengasumsikan $\rho=\frac{Q}{C}$ maka persamaan (14) dapat ditulis kembali sebagai persamaan berikut yang biasa disebut persamaan Davidson. Secara matematis, ciri tersebut dapat dinyatakan sebagai berikut:

$$
T_{Q}=T_{0}\left[\frac{1-(1-a) \frac{Q}{C}}{1-\frac{Q}{C}}\right]
$$

Dengan:

$\mathrm{T}_{\mathrm{Q}} \quad=$ waktu tempuh pada saat arus sama dengan $\mathrm{Q}$

$\mathrm{T}_{0} \quad$ = waktu tempuh pada arus sama dengan 0

$\mathrm{Q} \quad=$ arus lalu lintas

a $\quad=$ indeks tingkat pelayanan (ITP)

\section{Pendekatan Linier}

Persamaan (15) dapat disederhanakan dengan urutan penyederhanaan sebagai berikut:

$$
\begin{aligned}
& \frac{T_{Q}}{T_{0}}=1+\left[\frac{a\left(\frac{Q}{C}\right)}{1-\left(\frac{Q}{C}\right)}\right] \\
& \frac{T_{Q}}{T_{0}}=1+a \frac{Q}{C-Q} \\
& T_{Q}=T_{0}+a T_{0}\left[\frac{Q}{C-Q}\right]
\end{aligned}
$$

Persamaan (18) dapat disederhanakan dan ditulis kembali sebagai persamaan linier $Y_{i}=A+X_{i}$ dengan mengasumsikan $T_{Q}^{i}=Y_{i}$ dan $\frac{Q i}{C-Q i}=X_{i}$. Dengan mengetahui beberapa set data $T_{Q}^{i}$ dan $Q_{i}$ 
yang didapat dari survei waktu tempuh dan volume arus lalu lintas, maka dengan menggunakan analisa regresi linier, parameter A dan B dapat dihitung dengan persamaan berikut:

$$
B=\frac{\mathrm{N} \sum_{\mathrm{i}=1}^{\mathrm{N}}\left(\mathrm{X}_{\mathrm{i}} \mathrm{Y}_{\mathrm{i}}\right)-\sum_{\mathrm{i}=1}^{\mathrm{N}} \sum_{\mathrm{I}=1}^{\mathrm{N}}\left(\mathrm{Y}_{\mathrm{i}}\right)}{\mathrm{N} \sum_{\mathrm{i}=1}^{\mathrm{N}}\left(\mathrm{X}_{\mathrm{i}}\right)^{2}-\left(\sum_{\mathrm{i}=1}^{\mathrm{N}}\left(\mathrm{X}_{\mathrm{i}}\right)\right)^{2}}
$$

Sehingga, nilai indeks tingkat pelayanan (ITP) adalah $\mathrm{a}=\frac{\mathrm{B}}{\mathrm{A}}$.

\section{METODOLOGI PENELITIAN}

\subsection{Indetifikasi Permasalahan}

Tujuan dari identifikasi permasalahan adalah untuk mengetahui nilai indeks tingkat pelayanan (ITP), keadaan kondisi lalu lintas, volume lalu lintas, kecepatan, waktu tempuh jenis kendaraan di jalan Ponokawan sampai ruas jalan Mayjen Bambang Yuwono serta membuat peta jalan dengan bantuan Sistem Informasi Geografis (SIG).

\section{a. Studi Literatur}

Dalam penelitian ini studi yang dilakukan adalah mengenai pemetaan Indeks Tingkat Pelayanan (ITP) di ruas jalan Ponokawan sampai ruas jalan Mayjen Bambang Yuwono. Refrensi yang ada diantaranya adalah sumber terdahulu, internet, Tugas Akhir serta jurnal.

\section{b. Survei Lapangan}

Survey lapangan dilakukan dengan cara menentukan lokasi tujuan awal penelitian, kondisi keadaan lalu lintas yang terjadi agar dapat membantu mempermudah dalam proses pengumpulan data.

\subsection{Pengumpulan Data}

Pengumpulan data merupakan proses mendapatkan suatu yang diinginkan pada lokasi tertentu dengan waktu yang telah ditentukan. Data yang diperlukan adalah data primer dan data sekunder.

\section{a. Data Primer}

Dalam penelitian ini data primer yang di butuhkan adalah sebagai berikut :

1. Kecepatan kendaraan

2. Volume kendaraan

3. Jumlah jalur

4. Hambatan samping

5. Koordinat jalan

\section{b. Data Sekunder}

Data sekunder diperoleh dari suatu lembaga instansi pemerintahan, data yang dibutuhkan adalah letak geografis pada Peta RBI Krian. 


\section{ANALISA DATA DAN PEMBAHASAN}

\subsection{Data Karakteristik Jalan}

Pengambilan data jalan dilakukan dengan metode pengukuran langsung dilapangan dengan menggunakan alat bantu ukur meliputi rol meter, checker, dan stopwatch. Segmen jalan pada penelitian ini dibagi menjadi 7 segmen yaitu segmen I berada pada ruas Jalan Ponokawan, segmen II pada ruas Jalan Raya Kemasan, segmen III pada ruas Jalan Raya Krian, segmen IV pada ruas Jalan Basuki Rahmat, segmen V pada ruas Jalan Imam Bonjol, dan segmen VI dan VII pada ruas Jalan Mayjen Bambang Yuwono. Data spesifikasi jalan ditunjukkan pada tabel 4.1 berikut:

Tabel 4.1 Data Spesifikasi Jalan

\begin{tabular}{|c|c|c|c|c|c|}
\hline Segmen & Nama Jalan & $\frac{\text { Lebar }}{(\mathbf{m})}$ & $\frac{\text { Panjang }}{(\mathbf{m})}$ & Tipe & $\begin{array}{l}\text { Bahu } \\
\text { Jalan }\end{array}$ \\
\hline $\mathrm{I}$ & Jalan Ponokawan & 9 & 1550 & $2 / 2 \mathrm{UD}$ & 1 \\
\hline II & Jalan Raya Kemasan & 9 & 900 & $2 / 2 \mathrm{UD}$ & 1 \\
\hline III & Jalan Raya Krian & 9 & 800 & $2 / 2 \mathrm{UD}$ & 1 \\
\hline IV & Jalan Basuki Rahmat & 11 & 550 & $2 / 2 \mathrm{UD}$ & 1 \\
\hline $\mathrm{V}$ & Jalan Imam Bonjol & 11 & 950 & $2 / 2 \mathrm{UD}$ & 1,5 \\
\hline VI & $\begin{array}{c}\text { Jalan Mayjen } \\
\text { Bambang Yuwono }\end{array}$ & 10 & 1650 & $2 / 2 \mathrm{UD}$ & 1,5 \\
\hline VII & $\begin{array}{c}\text { Jalan Mayjen } \\
\text { Bambang Yuwono }\end{array}$ & 10 & 850 & $2 / 2 \mathrm{UD}$ & 1,5 \\
\hline
\end{tabular}

Sumber: Hasil Survei dan Perhitungan

\subsection{Perhitungan Volume Lalu Lintas}

Hasil dari survei volume kendaraan segmen I ruas Jalan Ponokawan pukul 08.00 - 10.00 WIB, pukul 10.00 - 14.00 WIB dan pukul 16.00 - 18.00 WIB dapat dilihat pada tabel 4.2.

Contoh perhitungan volume lalu lintas dalam satuan kend/jam:

a. $\mathrm{MC}=528+374+491+40(\mathrm{kend} / 15 \mathrm{menit})=1797(\mathrm{kend} / \mathrm{jam})$

b. $\mathrm{LV}=80+69+108+62$ (kend/15 menit)

$=319(\mathrm{kend} / \mathrm{jam})$

c. $\mathrm{HV}=26+23+26+30$ (kend/15 menit)

$=105(\mathrm{kend} / \mathrm{jam})$

Total volume lalu lintas $=2221(\mathrm{kend} / \mathrm{jam})$

Konversi satuan (kend/jam) untuk setiap jenis kendaraan ke satuan (smp/jam) dengan cara mengalikan hasil satuan (kend/jam) dengan koefisien (emp) dengan lebar tiap jalur 9 meter dua arah tanpa median. Maka volume kendaraan ringan (LV) dikalikan 1, kendaraan berat (HV) dikalikan 1,2 dan kendaraan sepeda motor (MC) dikalikan 0,25. 
Tabel 4.2 Data hasil Survei Segmen I

\begin{tabular}{ccccccccc}
\hline \multirow{2}{*}{ No } & $\begin{array}{c}\text { Periode } \\
\text { (WIB) }\end{array}$ & MC & LV & HV & MC & LV & HV & Total \\
\cline { 3 - 9 } & kend/jam & kend/jam & kend/jam & smp/jam & smp/jam & smp/jam & smp/jam \\
\hline 1 & $07.00-08.00$ & 1382 & 369 & 104 & 345,5 & 369 & 124,8 & 839,3 \\
\hline 2 & $08.00-08.15$ & 1295 & 393 & 101 & 323,75 & 393 & 121,2 & 837,95 \\
\hline 3 & $08.15-08.30$ & 1381 & 414 & 102 & 345,25 & 414 & 122,4 & 881,65 \\
\hline 4 & $08.30-08.45$ & 1380 & 419 & 94 & 345 & 419 & 112,8 & 876,8 \\
\hline 5 & $08.45-09.00$ & 1441 & 442 & 88 & 360,25 & 442 & 105,6 & 907,85 \\
\hline 6 & $12.00-13.00$ & 2179 & 557 & 216 & 544,75 & 557 & 259,2 & 1360,95 \\
\hline 7 & $13.00-13.15$ & 2079 & 550 & 234 & 519,75 & 550 & 280,8 & 1350,55 \\
\hline 8 & $13.15-13.30$ & 2095 & 571 & 245 & 523,75 & 571 & 294 & 1388,75 \\
\hline 9 & $13.30-13.45$ & 2087 & 604 & 238 & 521,75 & 604 & 285,6 & 1411,35 \\
\hline 10 & $13.45-14.00$ & 2046 & 602 & 226 & 511,5 & 602 & 271,2 & 1384,7 \\
\hline 11 & $16.00-17.00$ & 4829 & 576 & 98 & 1207,25 & 576 & 117,6 & 1900,85 \\
\hline 12 & $17.00-17.15$ & 4913 & 590 & 108 & 1228,25 & 590 & 129,6 & 1947,85 \\
\hline 13 & $17.15-17.30$ & 4967 & 603 & 103 & 1241,75 & 603 & 123,6 & 1968,35 \\
\hline 14 & $17.30-17.45$ & 5019 & 616 & 102 & 1254,75 & 616 & 122,4 & 1993,15 \\
\hline 15 & $17.45-18.00$ & 4881 & 603 & 102 & 1220,25 & 603 & 122,4 & 1945,65 \\
\hline & & Jumlah & & & 10493,5 & 7909 & 2593,2 & 20995,7 \\
\hline & & Rata-rata & & & 699,57 & 527,27 & 172,88 & 1399,71 \\
\hline
\end{tabular}

Sumber: Hasil Survei dan Perhitungan

Contoh perhitungan volume lalu lintas dalam satuan smp/jam:
a. QMC
$=1297(\mathrm{kend} / \mathrm{jam}) \times 0,25$
$=324,25(\mathrm{smp} / \mathrm{jam})$
b. QLV
$=289(\mathrm{kend} / \mathrm{jam}) \times 1$
$=289(\mathrm{smp} / \mathrm{jam})$
c. QHV
$=74(\mathrm{kend} / \mathrm{jam}) \times 1,2$
$=88,8(\mathrm{smp} / \mathrm{jam})$

Total volume lalu lintas $=702,05(\mathrm{smp} / \mathrm{jam})$

Tabel 4.3 Hasil Rekapitulasi Volume Lalu Lintas

\begin{tabular}{clc}
\hline Segmen & Nama Jalan & Volume (Q) Rata-rata \\
\hline I & Jalan Ponokawan & 1365,5 \\
\hline II & Jalan Raya Kemasan & 1399,7 \\
\hline III & Jalan Raya Krian & 1208,6 \\
\hline IV & Jalan Basuki Rahmat & 1120,5 \\
\hline V & Jalan Imam Bonjol & 980,1 \\
\hline VI & Jalan Mayjen Bambang Yuwono & 1329,2 \\
\hline VII & Jalan Mayjen Bambang Yuwono & 1199,7 \\
\hline
\end{tabular}

Sumber: Hasil Survei dan Perhitungan 
Hasil rekapitulasi volume lalu lintas dari segmen I Jalan Ponokawan sampai dengan segmen VII Jalan Mayjen Bambang Yuwono ditunjukkan pada tabel 4.3 diatas.

Berdasarkan tabel 4.3 hasil volume (Q) tertinggi terdapat pada segmen II Jalan Raya Kemasan (1399,7 smp/jam) dan volume terendah pada segmen V Jalan Imam Bonjol (980,1 smp/jam).

\subsection{Perhitungan Derajat Kejenuhan}

Perhitungan nilai derajat kejenuhan (DS) pada segmen I ruas Jalan Ponokawan dapat dilihat pada perhitungan berikut:

$\mathrm{DS}=\frac{\mathrm{Q}}{\mathrm{C}}=\frac{1365,49 \mathrm{smp} / \mathrm{jam}}{3407,50 \mathrm{smp} / \mathrm{jam}}=0,40$

$\mathrm{Q}=$ Hasil rekapitulasi perhitungan

$\mathrm{C}=$ Hasil perhitungan kapasitas jalan

Hasil perhitungan derajat kejenuhan (DS) pada ruas Jalan Ponokawan sampai ruas Jalan mayjen Bambang Yuwono ditunjukkan pada tabel 4.4. berikut:

Tabel 4.4 Hasil perhitungan derajat kejenuhan (DS)

\begin{tabular}{ccccc}
\hline \multirow{2}{*}{ Segmen } & Nama Jalan & Volume $(\mathbf{Q})$ & Kapasitas & \multirow{2}{*}{ DS } \\
\cline { 3 - 4 } & Jalan Ponokawan & Rata-rata & $\mathbf{( s m p / j a m )}$ & \\
\hline I & Jalan Raya Kemasan & 1365,49 & 3407,50 & 0,40 \\
\hline II & Jalan Raya Krian & 1208,59 & 3407,50 & 0,41 \\
\hline III & Jalan Basuki Rahmat & 1120,45 & 3691,70 & 0,30 \\
\hline V & Jalan Imam Bonjol & 980,10 & 3769,42 & 0,26 \\
\hline VI & $\begin{array}{c}\text { Jalan Mayjen } \\
\text { Bambang Yuwono }\end{array}$ & 1329,19 & 3516,25 & 0,38 \\
\hline VII & $\begin{array}{c}\text { Jalan Mayjen } \\
\text { Bambang Yuwono }\end{array}$ & 1199,69 & 3516,25 & 0,34 \\
\hline
\end{tabular}

Sumber: Hasil Survei dan Perhitungan

Hasil rekapitulasi perhitungan tabel 4.4., diperoleh nilai derajat kejenuhan (DS) terbesar adalah pada segmen II dengan nilai DS $(0,41)$ dan yang terkecil pada segmen V dengan nilai DS $(0,26)$.

\subsection{Perhitungan Kecepatan Arus Bebas}

Hasil perhitungan kecepatan arus bebas pada jalan Ponokawan sampai Jalan Mayjen Bambang Yuwono dapat dilihat pada tabel 4.5 berikut: 
Tabel 4.5 Data Hasil Perhitungan Kecepatan Arus Bebas

\begin{tabular}{ccccc}
\hline \multirow{2}{*}{ Segmen } & \multirow{2}{*}{ Nama Jalan } & \multicolumn{3}{c}{ Kecepatan arus bebas (km/jam) } \\
\cline { 3 - 5 } & Jalan Ponokawan & MC & LV & HV \\
\hline I & Jalan Raya Kemasan & 53,06 & 48,42 & 34,29 \\
\hline II & Jalan Raya Krian & 63,88 & 48,52 & 33,42 \\
\hline III & Jalan Basuki Rahmat & 53,38 & 48,85 & 36,93 \\
\hline IV & Jalan Imam Bonjol & 64,39 & 48,20 & 38,05 \\
\hline V & Jalan Mayjen & 61,07 & 48,75 & 33,79 \\
\hline VI & Bambang Yuwono & & \\
\hline VII & $\begin{array}{c}\text { lan Mayjen } \\
\text { Bambang Yuwono }\end{array}$ & 57,78 & 50,92 & 35,21 \\
\hline
\end{tabular}

\section{Sumber: Hasil Survei dan Perhitungan}

Berdasarkan Tabel 4.5 kecepatan arus bebas (FV) terbesar terdapat pada segmen V untuk kendaraan ringan (LV) sebesar 48,20 km/jam, untuk sepeda motor (MC) sebesar 64,39 km/jam dan untuk kendaraan berat (HV) sebesar 38,05 km/jam.

\subsection{Analisa Perhitungan Indeks Tingkat Pelayanan}

Hasil perhitungan indeks tingkat pelayanan dengan pendekatan linier ditunjukkan pada tabel 4.6.

Berdasarkan tabel 4.6 nilai A dan B dapat dihiung dengan menggunakan perhitungan sebagai berikut:

$$
\begin{aligned}
\mathrm{B} & =\frac{\mathrm{N} \sum_{\mathrm{i}=1}^{\mathrm{N}}\left(\mathrm{X}_{\mathrm{i}} \mathrm{Y}_{\mathrm{i}}\right)-\sum_{\mathrm{i}=1}^{\mathrm{N}}\left(\mathrm{X}_{\mathrm{i}}\right) \sum_{\mathrm{i}=1}^{\mathrm{N}}\left(\mathrm{Y}_{\mathrm{i}}\right)}{\mathrm{N} \sum_{\mathrm{i}=1}^{\mathrm{N}}\left(\mathrm{X}_{\mathrm{i}}\right)^{2}-\left[\sum_{\mathrm{i}=1}^{\mathrm{N}}\left(\mathrm{X}_{\mathrm{i}}\right)\right]^{2}} \\
& =\frac{(15 \times 0,01404)-(12,0582 \times 0,01693)}{(15 \times 14,0767)-(12,0582)^{2}}=0,00010 \\
\mathrm{~A} & =\overline{\mathrm{Y}}-\mathrm{B} \overline{\mathrm{X}} \\
& =0,00113-(0,00010 \times 0,8039)=0,00105
\end{aligned}
$$

Indeks tingkat pelayanan (a)

$=\frac{\mathrm{B}}{\mathrm{A}}=\frac{0,000010}{0,00105}=0,093$

Berdasarkan analisa perhitungan diperoleh nilai $\mathrm{T}_{0}=\mathrm{A}=0,000105$ dan indeks tingkat pelayanan $\mathrm{a}=0,093$ dengan jenis tingkat pelayanan A dimana dalam kondisi arus bebas dengan kecepatan tinggi dan volume lalu lintas rendah, pengemudi dapat memilih kecepatan yang diinginkan. 
Tabel 4.6 Index Tingkat Pelayanan

\begin{tabular}{|c|c|c|c|c|c|c|c|}
\hline \multirow[t]{2}{*}{ No } & $\begin{array}{c}\text { TQ } \\
\text { (menit) }\end{array}$ & $\begin{array}{r}\mathrm{TQ}=\mathrm{Yi} \\
(\text { jam }) \\
\end{array}$ & $\begin{array}{c}\text { Qi } \\
\text { (smp/jam) }\end{array}$ & (C-Qi) & $\mathrm{Qi} /(\mathrm{C}-\mathrm{Qi})=\mathrm{Xi}$ & $\mathrm{Xi}-\mathrm{Yi}$ & $\mathrm{Xi}^{\wedge} 2$ \\
\hline & [1] & {$[2]=[1] / 60$} & [3] & {$[4]=\mathrm{C}-[3]$} & {$[5]=[3] /[4]$} & {$[6]=[2] *[5]$} & {$[7]=[5]^{\wedge} 2$} \\
\hline 1 & 0,0634 & 0,001057 & 702,1 & 2698,0 & 0,2602 & 0,000275 & 0,06771 \\
\hline 2 & 0,0644 & 0,001073 & 712,3 & 2687,7 & 0,2650 & 0,000284 & 0,07024 \\
\hline 3 & 0,0643 & 0,001072 & 723,1 & 2677,0 & 0,2701 & 0,000289 & 0,07296 \\
\hline 4 & 0,0674 & 0,001123 & 763,9 & 2636,1 & 0,2898 & 0,000326 & 0,08397 \\
\hline 5 & 0,0635 & 0,001058 & 807,5 & 2592,5 & 0,3115 & 0,000330 & 0,09702 \\
\hline 6 & 0,0623 & 0,001038 & 1256,9 & 2143,1 & 0,5865 & 0,000609 & 0,34397 \\
\hline 7 & 0,0672 & 0,001120 & 1327,2 & 2072,8 & 0,6403 & 0,000717 & 0,40998 \\
\hline 8 & 0,0693 & 0,001155 & 1386,9 & 2013,1 & 0,6889 & 0,000796 & 0,47463 \\
\hline 9 & 0,0668 & 0,001113 & 1377,7 & 2022,3 & 0,6813 & 0,000758 & 0,46411 \\
\hline 10 & 0,0695 & 0,001158 & 1367,9 & 2032,1 & 0,6731 & 0,000780 & 0,45313 \\
\hline 11 & 0,0661 & 0,001102 & 1909,1 & 1491,0 & 1,2804 & 0,001411 & 1,63949 \\
\hline 12 & 0,0714 & 0,001190 & 1931,8 & 1468,3 & 1,3157 & 0,001566 & 1,73102 \\
\hline 13 & 0,0739 & 0,001232 & 1932,6 & 1467,4 & 1,3170 & 0,001622 & 1,73455 \\
\hline 14 & 0,0708 & 0,001180 & 1951,4 & 1448,7 & 1,3470 & 0,001589 & 1,81444 \\
\hline 15 & 0,0756 & 0,001260 & 2332,3 & 1067,8 & 2,1843 & 0,002752 & 4,77102 \\
\hline & Alah & 0,016932 & & & 12,1111 & 0,014104 & 14,22823 \\
\hline & -rata & 0,001129 & & & 0,80741 & 0,00094 & 0,94855 \\
\hline
\end{tabular}

Tabel 4.7 Data Hasil Perhitungan Indeks Tingkat Pelayanan

\begin{tabular}{|c|c|c|c|}
\hline $\begin{array}{c}\text { Hari } \\
\text { Tanggal } \\
\end{array}$ & Segmen & ITP & Jenis ITP \\
\hline $\begin{array}{c}\text { Senin } \\
21 \text { Oktober } 2019\end{array}$ & $\begin{array}{c}\text { Segmen I } \\
\text { Jalan Ponokawan } \\
\end{array}$ & 0,093 & A \\
\hline $\begin{array}{c}\text { Senin } \\
21 \text { Oktober } 2019\end{array}$ & $\begin{array}{c}\text { Segmen II } \\
\text { Jalann Raya Kemasan }\end{array}$ & 0,141 & A \\
\hline $\begin{array}{c}\text { Selasa } \\
22 \text { Oktober } 2019\end{array}$ & $\begin{array}{c}\text { Segmen III } \\
\text { Jalan Raya Krian } \\
\end{array}$ & 0,074 & A \\
\hline $\begin{array}{c}\text { Selasa } \\
22 \text { Oktober } 2019\end{array}$ & $\begin{array}{c}\text { Segmen IV } \\
\text { Jalan Basuki Rahmat }\end{array}$ & 0,210 & B \\
\hline $\begin{array}{c}\text { Rabu } \\
23 \text { Oktober } 2019\end{array}$ & $\begin{array}{c}\text { Segmen V } \\
\text { Jalan Imam Bonjol }\end{array}$ & 0,130 & A \\
\hline $\begin{array}{c}\text { Rabu } \\
23 \text { Oktober } 2019\end{array}$ & $\begin{array}{c}\text { Segman VI } \\
\text { Jalan Mayjen Bambang Yuwono }\end{array}$ & 0,109 & A \\
\hline $\begin{array}{c}\text { Rabu } \\
23 \text { Oktober } 2019\end{array}$ & $\begin{array}{c}\text { Segmen VII } \\
\text { Jalan Mayjen Bambang Yuwono }\end{array}$ & 0,113 & A \\
\hline
\end{tabular}

Sumber: Hasil Survei dan Perhitungan

Hasil dari analisa perhitungan yang dilakukan dengan menggunakan metode regresi linier, maka diperoleh nilai indeks tingkat pelayanan pada ruas Jalan Ponokawan sampai ruas Jalan Mayjen Bambang Yuwono dapat dilihat pada tabel 4.7. Dari hasil rekapitulasi analisa perhitungan ITP 
dengan pendekatan linier pada tabel 4.7 didapatkan nilai terbesar pada hari Selasa 22 Oktober 2019 segmen IV dengan ITP a = 0,210 (B). Sedangkan nilai terkecil pada hari Selasa, 22 Oktober 2019 segmen III dengan ITP $\mathrm{a}=0,074(\mathrm{~A})$.

\subsection{Pemetaan Sistem Informasi Geografis Dengan Software}

Pengolahan pemetaan Sistem Informasi Geografis dengan software dilakukan setelah penelitian dan perhitungan untuk mendapatkan data spasial. Data atribut merupakan data yang mempresentasikan aspek-aspek deskripsi / penjelasan dari suatu fenomena di permukaan bumi dalam bentuk kata-kata, angka, atau tabel. Data atribut yang ditampilkan adalah, nama jalan, panjang dan lebar jalan, koordinat jalan, dan nilai Indeks Tingkat Pelayanan.

Hasil pemetaan SIG dengan menggunakan software ditunjukkan pada gambar-gambar berikut:

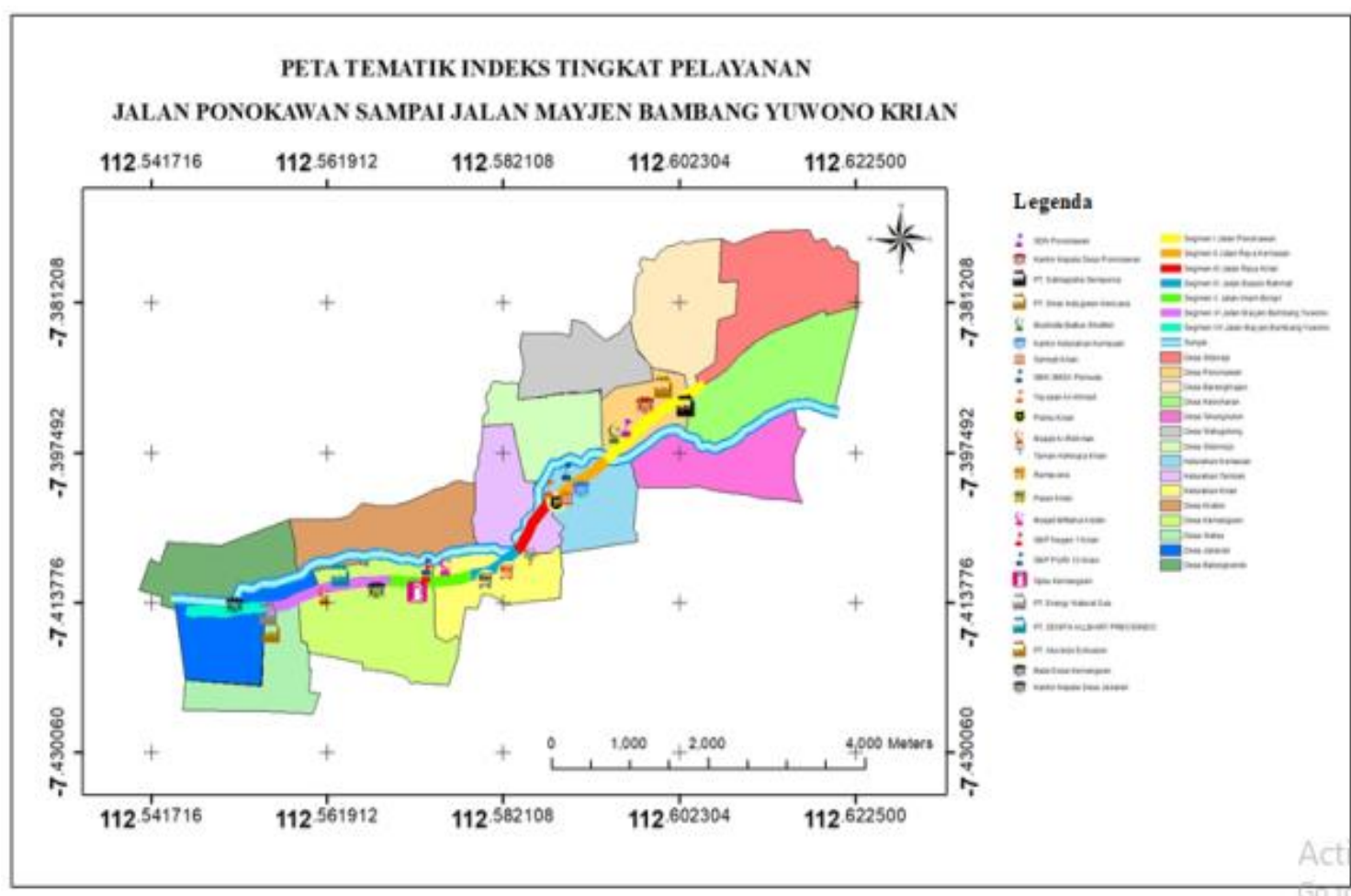

Gambar 2. Peta Tematik Line,Point, dan polygon 


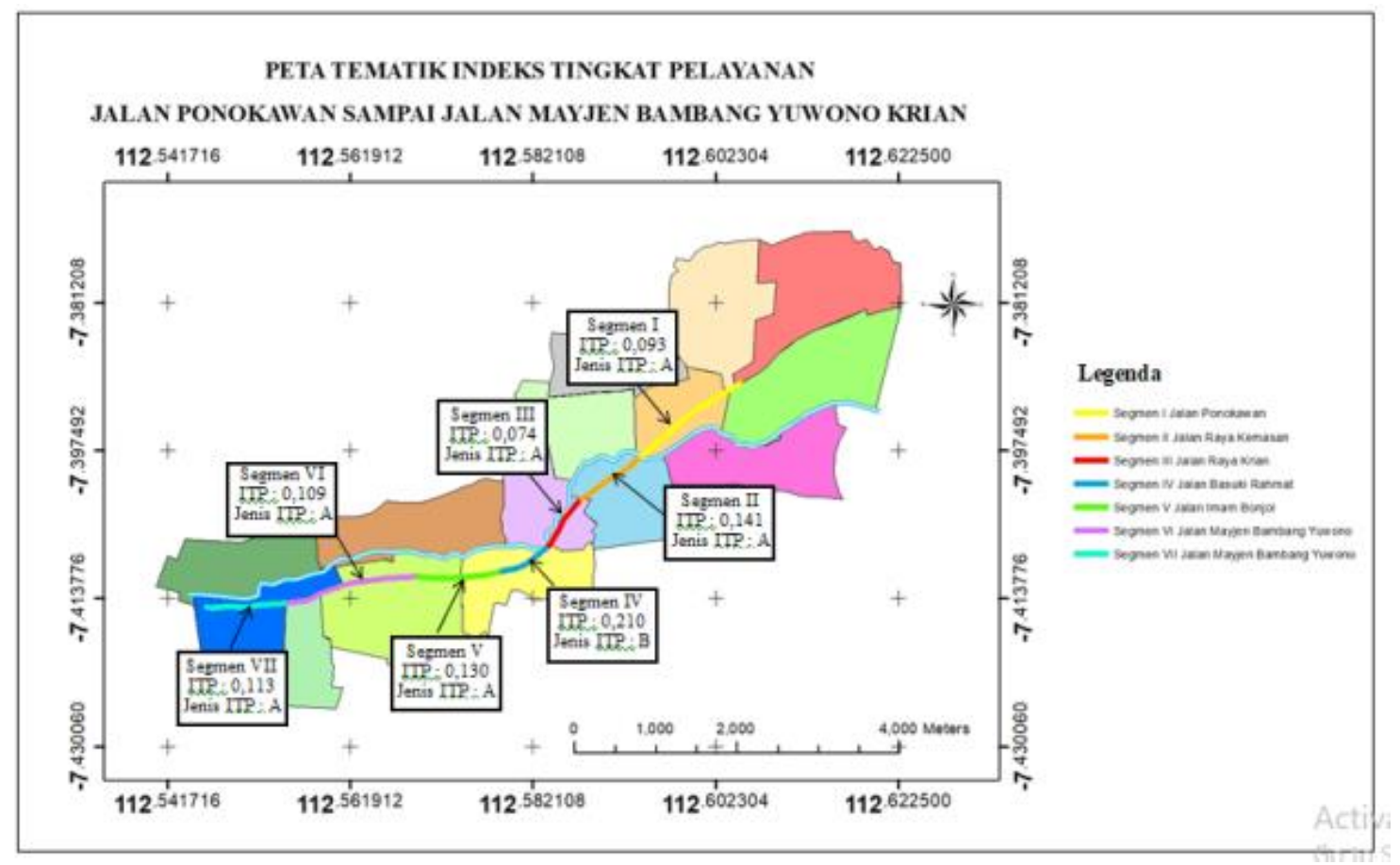

Gambar 3. Peta Tematik Line (Jalan)

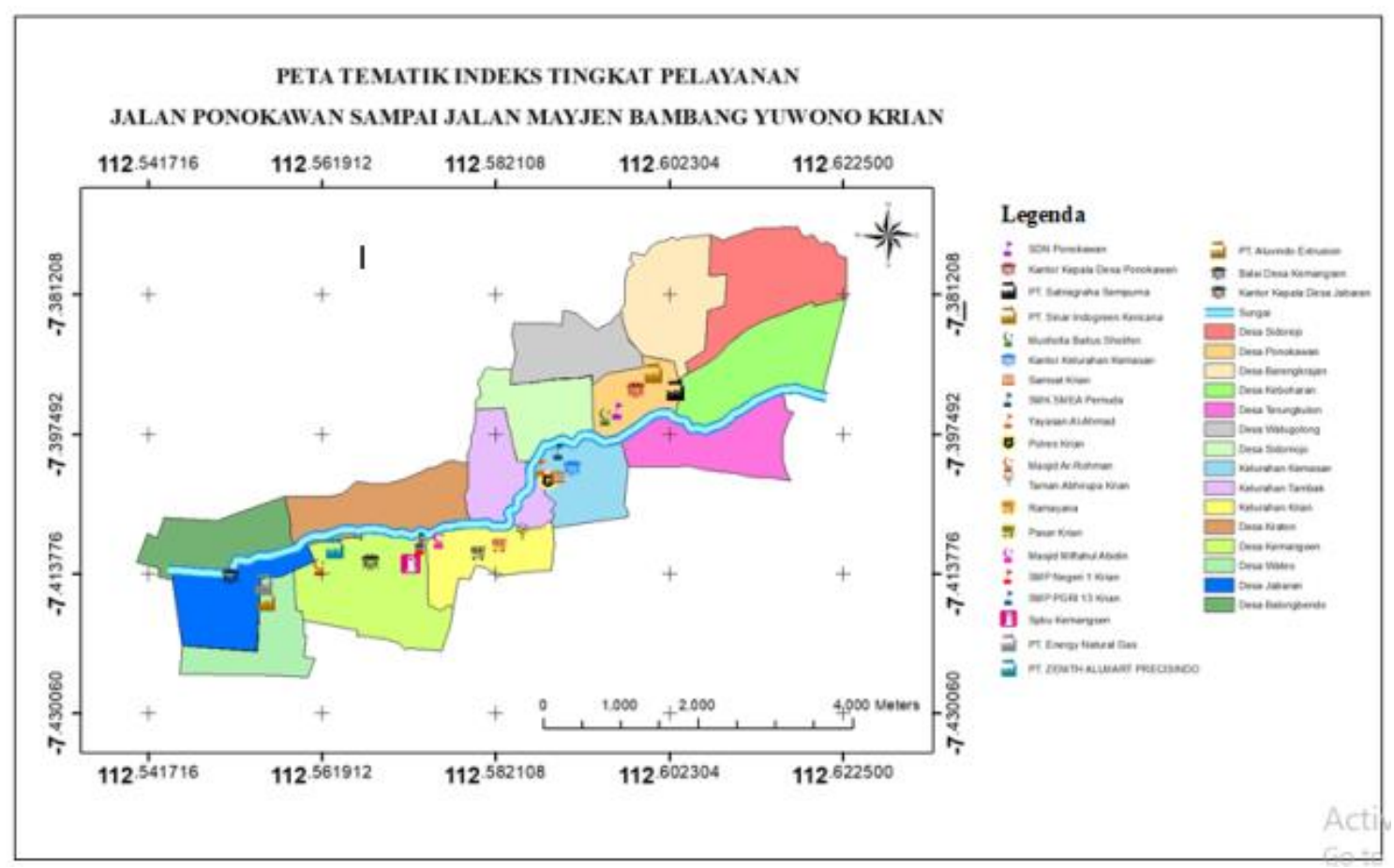

Gambar 4. Peta Tematik Polygon (Batas Wilayah) 


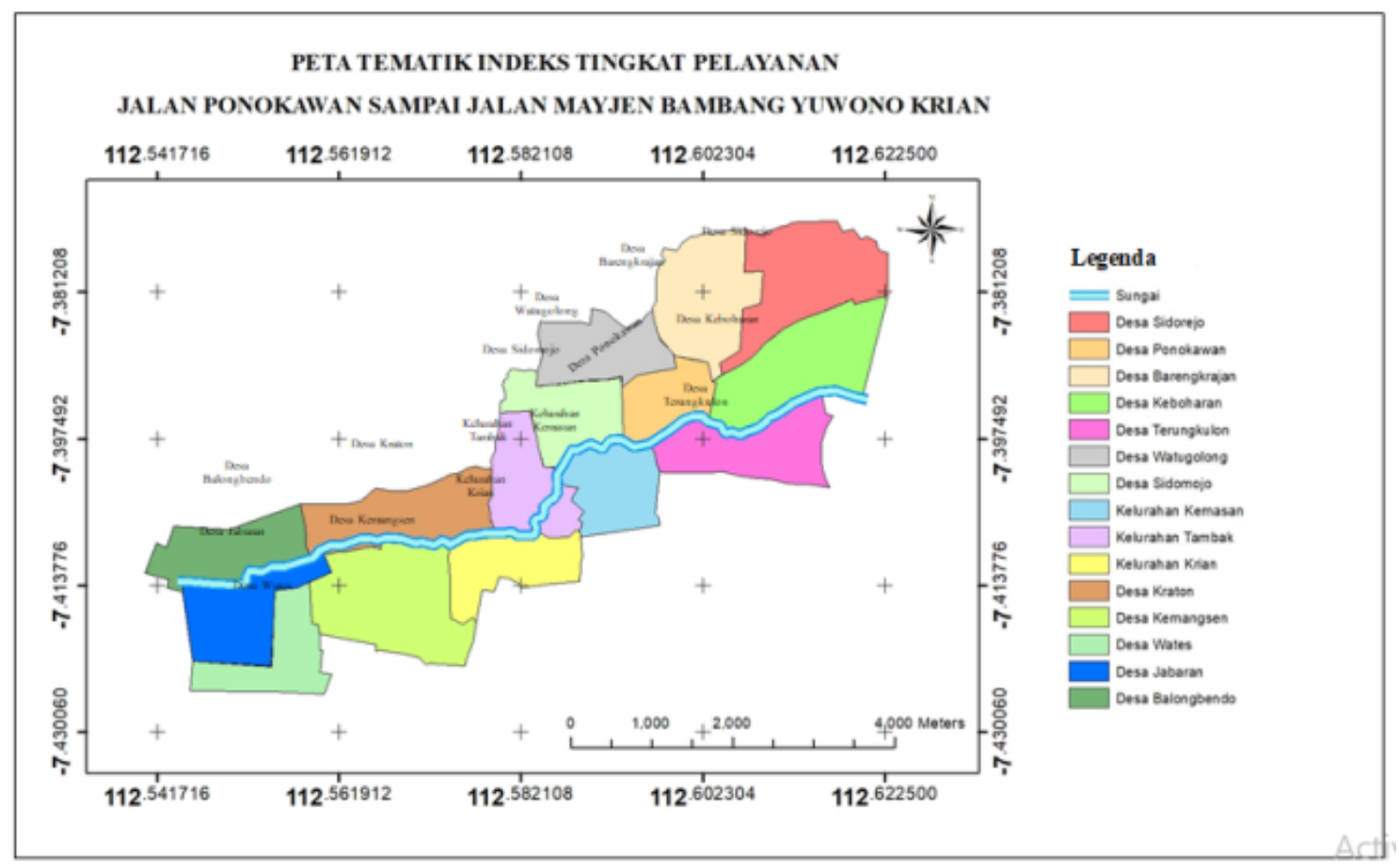

Gambar 5. Peta Tematik Point (Gedung/bangunan penting)

\section{KESIMPULAN}

Berdasarkan dari hasil penelitian didapatkan kesimpulan sebagai berikut :

1. Dari hasil analisa dan perhitungan volume yang telah dilakukan pada tiap segmen diperoleh nilai volume lalu lintas rata-rata terbesar pada segmen II Jalan Raya Kemasan dengan total volume kendaraan 1577,5 smp/jam.

2. Kecepatan arus bebas (FV) terbesar untuk kendaraan ringan (LV) pada segmen VII sebesar 50,92 $\mathrm{km} / \mathrm{jam}$, untuk sepeda motor (MC) pada segmen II sebesar 63,88 km/jam, dan untuk kendaraan berat (HV) pada segmen V sebesar 41,06 km/jam.

3. Hasil perhitungan dengan menggunakan metode regresi linier di peroleh nilai a (Indeks Tingkat Pelayanan) segmen I (0,093; A), segmen II (0,141; A), segmen III (0,074; A), segmen IV (0,210; B), segemen V (0,13; A), segmen VI (0,109; A), dan segmen VII (0,113; A)

4. Pemetaan nilai indeks tingkat pelayanan secara digitasi pada gambar 4.2 sampai dengan gambar 4.4 memberikan hasil yang cukup signifikan

\section{Ucapan Terima Kasih}

Penulis mengucapkan terima kasih kepada Laboratorium SIG Teknik Sipil UPN Veteran Jawa Timur yang telah membantu pengolahan data SIG, Tata Usaha Fakultas dan LPPM UPN Veteran Jawa Timur yang telah memberi kemudahan selama proses administrasi, serta teman-teman jurusan Teknik Sipil UPN Veteran Jawa Timur yang telah membantu perolehan data lapangan. 


\section{Daftar Pustaka}

Afonso, P., Santana, A., Afonso, P., Zanin, A., \& Wernke, R. (2019). ScienceDirect ScienceDirect Costing models for capacity optimization in Industry 4.0: Trade-off between used capacity and operational efficiency. https://doi.org/10.1016/j.promfg.2019.02.197

Alekseeva, N., Tanev, I., \& Shimohara, K. (2018). Evolving the Controller of Automated Steering of a Car in Slippery Road Conditions. Algorithms, 11(7), 108. https://doi.org/10.3390/a1 1070108

Dewan, K. K., \& Ahmad, I. (2007). Carpooling: A Step To Reduce Congestion (A Case Study of Delhi). Traffic.

Jain, V., Sharma, A., \& Subramanian, L. (2012). Road traffic congestion in the developing world. Proceedings of the 2nd ACM Symposium on Computing for Development ACM DEV '12. https://doi.org/10.1145/2160601.2160616

Li, F., Li, S., Zhu, C., Lan, X., \& Chang, H. (2017). Cost-effective class-imbalance aware $\mathrm{CNN}$ for vehicle localization and categorization in high resolution aerial images. Remote Sensing, 9(5), 1-29. https://doi.org/10.3390/rs9050494

Lindsey, C. R., \& Verhoef, E. T. (2000). Congestion Modelling. Handbooks in Transport, Volume 1: Handbook of Transport Modelling.

Rhee, K.-A., Kim, J.-K., Lee, Y.-I., \& Ulfarsson, G. F. (2016). Spatial regression analysis of traffic crashes in Seoul. Accident Analysis and Prevention, 91, 190-199. https://doi.org/10.1016/j.aap.2016.02.023

Tamin, O. Z. (2003). Perencanaan dan Permodelan Transportasi, contoh soal dan aplikasi (First Edit). ITB.

Waqas, M., Dong, Q., Ahmad, N., Zhu, Y., \& Nadeem, M. (2018). Understanding Acceptability towards Sustainable Transportation Behavior: A Case Study of China. Sustainability, 10(10), 3686. https://doi.org/10.3390/su10103686

Wibisana, Hendra. (2007). Studi Hubungan Arus Lalu Lintas di Ruas Jalan Rungkut Asri Kota Madya Surabaya Dengan Metode Underwood. Jurnal Teknik Sipil, 3(2), 103112. https://journal.maranatha.edu/index.php/jts/article/view/1282

Wibisana, Hendrata, \& Utomo, N. (2016). Pemetaan Kecepatan dan Kerapatan Lalu Lintas di Ruas Jalan Arteri Kota Surabaya. Jurnal Teknik Sipil, 12(2), 121-145. https://journal.maranatha.edu/index.php/jts/article/view/1420 